\title{
CONTINUING PROFESSIONAL DEVELOPMENT (CPD) IN NEPAL AND ITS CHALLENGES
}

\author{
Shatdal Chaudhary, ${ }^{1}$ Nagendra Chaudhary ${ }^{2}$ \\ 1. Department of Internal Medicine, Universal College of Medical Sciences, Bhairahawa, Nepal \\ 2. Department of Pediatrics, Universal College of Medical Sciences, Bhairahawa, Nepal
}

Continuing professional development (CPD) is currently a much discussed topic among medical fraternity in Nepal. CPD may be defined as a lifelong, uninterrupted learning process whereby physicians maintain and improve standards of medical practice through the development of knowledge, skills, attitudes and behavior.

Continuing medical education (CME) is rapidly evolving into competency-based CPD. The main objective of introducing CPD is that one-time examination for doctors is not sufficient, especially, when the knowledge and practices in medicines are changing fast. ${ }^{2}$ An expectation from a good doctor is to serve the patient well with the latest modalities of diagnostics and therapeutics. The society also demands a competent doctor with up to date in his clinical area.

Nepal medical council (NMC) is planning to introduce CPD compulsorily in near future. ${ }^{4}$ As per present plan of $\mathrm{NMC}$, each registered doctor (MBBS and specialists) has to accumulate $100 \mathrm{CPD}$ points in next 5 years to constantly update their academic achievements either in the form of fellowships, conferences or CME. All of these records have to be submitted to the NMC which will then decide whether the doctor is eligible to continue treating patients. Once the doctor candidate acquires the target CPD points, he is eligible to renew his license and practice medicine. ${ }^{5}$

Among 100 points, each doctor, regardless of the specialty, should attend 30 points mandatory trainings on basic life support; professional ethics and communication; infection prevention and control; rational use of drugs; medical emergencies in dental practices and practice management in dentistry. Rest of 70 points can be earned through fellowships, conferences, research work and CMEs. All of these records should be submitted to the NMC to renew their medical license. The medical license will be revoked if someone fails to meet the required benchmark set by the NMC. ${ }^{5}$

Medicine is a constantly changing field due to arrival of new information and advancement in technology which makes it a lifelong learning subject. Life long learning has always been formally considered an ethical obligation of doctors. As a medical practitioner, all of us need to keep abreast with these changes in order to deliver the best possible management and care to our patients. Till date in Nepal, once the doctor passes his/her NMC licensing exam, there is no any provision to check whether the doctor has been practicing old, outdated, wrong concept in treating his patients or is being updated regularly. Traditionally, acquisition of knowledge and skill is being done by CME. CME describes continuing education in the field of knowledge and skills of medical practice in the form of formal lectures or seminars with time based credit points awarded. CPD is a broader concept, it includes all activities that doctors undertake, formally and informally, in order to maintain, update, develop and enhance their knowledge, skills and attitudes in response to the needs of their patients including medical, managerial, ethical, social, and personal skills. Engaging in CPD is a professional obligation but also a prerequisite for enhancing the quality of health care. The strongest motivating factor for continuous professional life-long learning is the will and desire to maintain professional quality. The concept of CPD is the need of time.

However, implementation of any programme (CPD) for the first time has to face a huge challenge. We should be able to change the educational behaviour of the doctor by explaining the gains of doing CPD, the loss of not doing it, the capability of doing it and marginal cost of doing it. It needs proper planning, coordination and should be done in transparent and accountable way. The NMC should make sure that these courses are easily available to doctors working in the any part of the country especially in the rural areas without disturbing their clinical work at free of cost. It may not be feasible for a doctor working in a remote hilly region to travel a huge distance to the capital or major city leaving their work station. This may lead to negative impact in the services provided to the community and patients.

We feel that the successful implementation of the CPD in a developing nation like Nepal has a huge challenge to face in upcoming days The NMC should also think of the alternatives to those doctors who have already cleared their graduation/post-graduation along with their NMC licensing examination but have failed to attain the CPD credit points as described by the NMC. If those doctors are really not allowed to practice medicine or treat patients, it is going to hamper the health care system of Nepal badly where we still don't have 
adequate number of doctors in the country and majority of the vacancies are empty in many remote areas. Again, issues and concerns for those doctors who have a permanent government job (Lok Sewa) but are unable to collect 100 CPD points in the 5-year duration should be addressed and well defined. Availability of CPD trainers/providers and selection of such providers is also a challenging task. The question regarding how those trainers are going to be trained (Training of trainers, TOT) and the eligibility criteria for those trainers need to be addressed for successful implantation of the programme.

CPD itself is a good concept to garnish one's knowledge and implement in patient care. Doctors should be supported to undertake CPD financially with grants which will help the programme to flourish in the country and will be acceptable to everyone. Besides, the NMC should also work closely with various other health organizations, medical societies, medical schools and the ministry of health to make these courses readily available for doctors across the country. Instead of formal lecture, personally designed CPD reflects adult learning principles of autonomy, self-direction, goal orientation, and practice-based learning. Online internet based resources should be more and more encouraged. Customization is needed according to local needs while developing the CPD activities keeping the universal guidelines and principles into consideration. Initially, voluntary CPD without legal obligation should be started which can be made mandatory in due course once it is properly developed and established.

\section{REFERENCES}

1. Chief Medical Officer. A Review of Continuing Professional Development in General Practice. Wethery: Department of Health, 1998

2. Balmer JT. The transformation of continuing medical education (CME) in the United States. Adv Med EducPract 2013;4:17182.

3. Moja L, Kwag KH. Point of care information services: a platform for self-directed continuing medical education for front line decision makers. Postgrad Med J 2015;91:83-91.

4. Nepal Medical Council, CPD committee. Report of the stakeholders' meeting on CPD in Nepal. Kathmandu: Nepal Medical Council;2013 Dec 28.

5. https://kathmandupost.ekantipur.com/news/2017-05-08/nmcto-bring-cpd-grading-for-docs-to-set-practice benchmark. html.

DOI: https://doi.org/10.3126/jucms.v7i1.24675 